\title{
Rice Grain in Uterine Cavity: Rare Presentations in Rural Nepalese Postmenopausal Farmer with Uterovaginal Prolapse
}

\author{
1Josei Baral, ${ }^{2}$ Ashma Rana, ${ }^{3}$ Geeta Gurung
}

\begin{abstract}
Background: Foreign bodies are less common in uterine cavity than vagina, and are less frequently seen in older women than prepubertal or premenarchal girls. When found in the uterus, these foreign bodies are usually forgotten intrauterine contraceptive device or retained fetal bones, objects which were introduced in the former case or the remnants of conceptus parts that was inadvertently retained as in the latter circumstances. Here, we are going to concentrate in foreign body that made its way into the uterine cavity unaided.
\end{abstract}

Aim: To study rice grain as retained intrauterine foreign body in women with prolapsed uterus.

Methods: Collection of series of cases of rice grain in the uterine cavity of women exposed to vaginal hysterectomy and pelvic floor repair for uterine prolapse from the year 2004 till date, from the Department of Obstetrics and Gynecology, Tribhuvan University Teaching Hospital, Kathmandu, Nepal.

Results: The rice grains as foreign body were entirely seen in postmenopausal multiparous women with the long standing cases of major degree of uterovaginal prolapse, chronicity affirmed by cervical hypertrophy and keratinization. These intrauterine rice grains, 1 to 3 in numbers were found at various level within the uterine cavity with resultant pyometra formation and urinary retention posing surgical difficulties in two cases.

Conclusion: Possibilities of rice grain as foreign body must be kept in mind in the complicated cases of uterovaginal prolapse posted for hysterectomy.

Keywords: Intrauterine foreign body, Rice grain, Uterine prolapse, Pyometra.

How to cite this article: Baral J, Rana A, Gurung G. Rice Grain in Uterine Cavity: Rare Presentations in Rural Nepalese Postmenopausal Farmer with Uterovaginal Prolapse. J South Asian Feder Menopause Soc 2014;2(2):79-82.

Source of support: Nil

Conflict of interest: None

\section{INTRODUCTION}

Foreign bodies retained in the uterine cavity are fetal bones due to incomplete abortion, forgotten intrauterine

\footnotetext{
${ }^{1}$ Associate Professor, ${ }^{2,3}$ Professor

${ }^{1-3}$ Department of Obstetrics and Gynecology, TU Teaching Hospital, Maharajgunj, Kathmandu, Nepal
}

Corresponding Author: Ashma Rana, Professor, Department of Obstetrics and Gynecology, TU Teaching Hospital Maharajgunj, Kathmandu, Nepal, Phone: +977-9851048763 e-mail:njog63@gmail.com contraceptive devices (IUCD) or iatrogenically left substance or instruments inadvertently. ${ }^{1-12}$ Ours was unusual experience of finding a rice grain/s (one to three in number) in different location of the uterine cavity on cut section of specimen of uterus removed at surgery for uterovaginal prolapse (UVP).

Paddy grain in eye has been reported as foreign body. By this article we intend to disseminate, rare coincidence of rice grain/s in the uterine cavity, which made their way through the cervical opening of prolapsed uterus, remaining outside vaginal, in rural Nepalese working in rice field.

\section{METHODS}

This study was carried in TU Teaching Hospital from 2004 till date, wherein all the women undergoing hysterectomy for uterovaginal prolapse were tracked preoperatively and clinically evaluated. Uterine specimen, removed at vaginal hysterectomy following prolapse surgery was carefully cut, to note presence of rice grain/s, number/s and their position and captured by camera for the evidences. Findings were clinically correlated with the preoperative presentation, saved in computer until more than a dozen cases were collected. To avoid miss outs or duplications, Gregorian calendar date on the digitalized picture was converted to Nepali date in Bikram Sambat and rechecked in operation register to verify that the case was genuine.

\section{RESULTS}

In an average, hysterectomy for UVP varied from 80 to 105 annually. Of all the cases of UVP surgically treated by vaginal hysterectomy, 15 cases were ascribed to having rice grain within the uterus.

Mean age of these women at presentation 63 (48-79); mean parity at presentation was 5.3 [parity ranged (3-9)]. All the women were postmenopausal and having had attained menopause at 47 years, which was the mean age at menopause (44-52) (Table 1).

History of the women revealed that the suffering from fallen womb, on an average was 22 years [(2-40 years)] with the inclusion of a case of UVP documented since a very young age of 15-year (before child birth) recorded 
Table 1: Factors influencing uterovaginal prolapse

\begin{tabular}{lll}
\hline Etiological factors & Range & Mean \\
\hline Age & $48-79$ & 62.3 \\
Menopausal age & $44-52$ & 47 \\
Parity & $3-9$ & 5.3 \\
Age at prolapse & $15-60$ & 36.1 \\
Duration of prolapse & $2-40$ & 21.6 \\
\hline
\end{tabular}

as an example of rare case of congenital uterine prolapse. And, excepting this case of congenital prolapse, there were equal number of women who related their morbidities from UVP either from childbirth (first, second or last childbirth) or menopause.

But, the duration of suffering in years drastically differed in the two groups: reproductive etiology [mean duration: 32 years and range (28-40)] than menopause related UVP [mean duration in years: 9 and range (2-20)].

Primarily, all of them were indulged in the farming occupation and came from rural villages with different kind of life style, not habituated in wearing undergarments.

\section{Symptoms}

Apart from something coming out per vagina, a classic presentation of UVP, backache, pain in lower abdomen, vaginal discharge and urinary symptoms like dysuria and retention were also the presenting complaints.

Vaginal discharge was seen in three cases. Discharge was foul smelly in one but mucoid in two other cases. The last two cases each were associated with dysuria in one case and pain abdomen in another. Abdominal pain was also seen in one additional case. Urinary problem was seen in total three cases, already described is a case associated with vaginal discharge for 5 years, second one presented with recurrent episode of urinary tract infection with $E$. coli and pseudomonas finally before going to urinary retention for 2 days, before admission.

Other associated medical complications were moderate anemia where 2 unit of blood transfusion was given to correct hemoglobin of $7 \mathrm{gm}$ percent. Of the other two cases, one had renal cortical cyst and other had cardiac problem with constricted ventricles.

During routine preoperative assessment usually done, 1 day prior to operation, keratinization of cervix (Fig. 1A) was found in a case, along with chronic cervical hypertrophy (Fig. 2), latter was conferred in all most all cases except one. At the same time, rice grain in the uterine cavity (Fig. 3) was detected during transvaginal ultrasound of gynecology department placed in preoperative room.

Coming to the operation, duration of UVP surgery was related to the presence of the cystocele, rectocele, huge enterocele, complete eversion of vagina and recently healed decubitus ulcer. These factors cumulatively posed

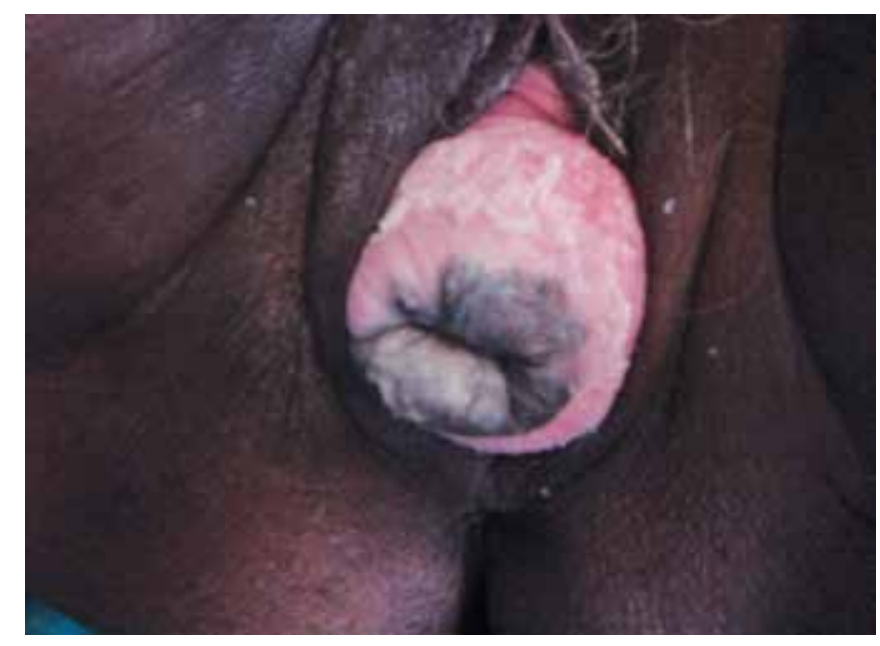

Fig. 1A: Keratinization seen in third degree uterovaginal prolapse

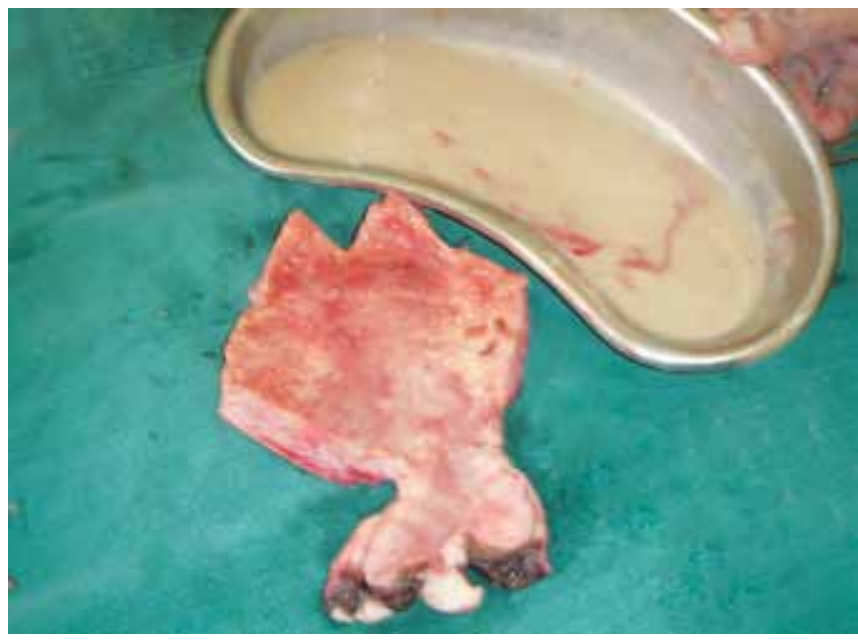

Fig. 1B: Husk covered full rice grain in uterovaginal prolapse with hypertrophied cervix

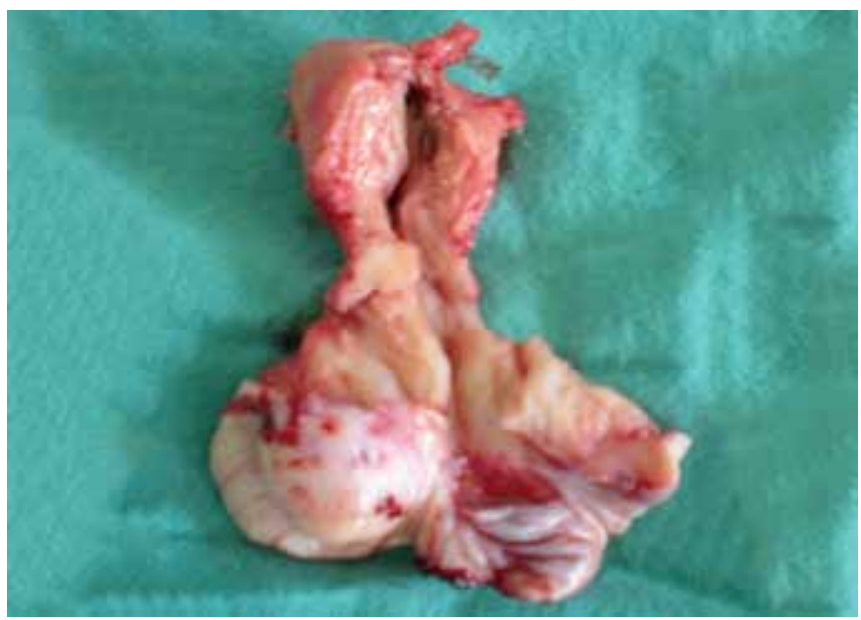

Fig. 2: Pus being drained-a case of pyometra, the collection of pus occurred due to presence of rice grains

difficulty in tissue dissection or defining proper cleavage. In other words, surgery was not very simple for those having UVP for many years with hypertrophied cervix or keratinization with mean surgical duration of 1 hour and 15 minutes. 


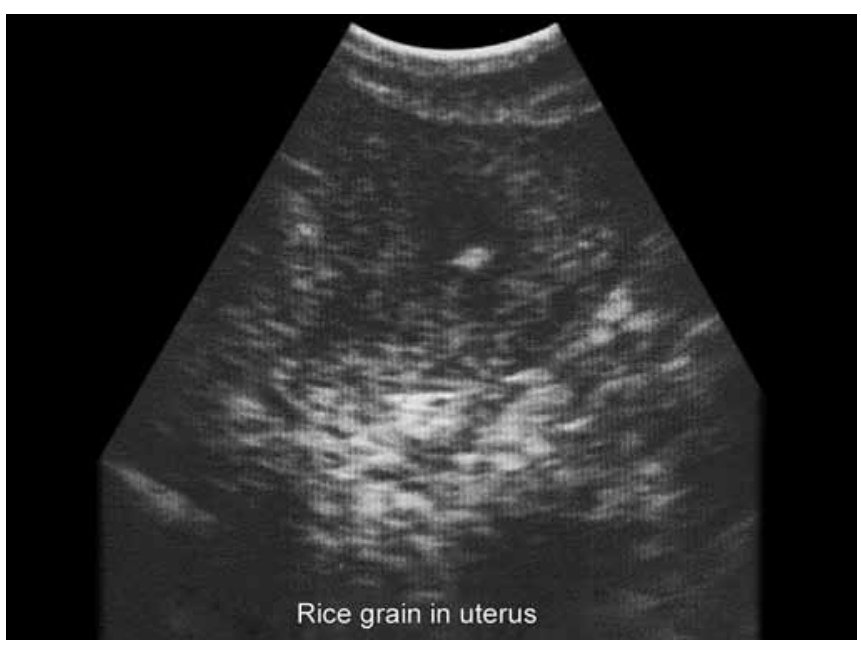

Fig. 3: Rice grain was detected during transvaginal ultrasound

Surgical difficulty was depreciated in the following three cases:

1. A simple looking third degree UVP with keratinization (Fig. 2) had a deceptive look, surgery not being as simple to deliver the uterus. At an attempt of hemisection of uterus, a gush of pus overflowed (about $400 \mathrm{ml}$ ). It was a case of pyometra formed due to foreign body, rice grain in the uterine cavity. Uterus along cervix measured $13 \mathrm{~cm}(8+5)$.

2. Additional case of pyometra $(50 \mathrm{ml})$, found on section of specimen.

3. UVP treated for decubitus ulcer for more than 6 weeks (Fig. 1B) in a case of procidentia with huge hypertrophied cervix.

Cut section of uterus revealed rice grain [one (10), 2 (4) and 3(1)]. These rice grains were predominantly located in the body of uterus [on the upper part of the cervical canal (1), endometrial cavity (7), fundus (4) and uterotubal junction (3)]. Except for the fresh look of the grains in 3 cases, in rest of the cases they appeared dark and decayed indicating that the foreign body had been retained for quite some time.

In two cases, pyometra was associated complication from rice grain/s concealed in the thick and turbid pus, in both women who had attained menopause at 45 years and had urinary problem. They were-in sixth and seventh decade of life, with parity $3 / 5$; UVP since the age of 32 and 58 years with the duration of suffering for 28/12 years, having had UVP related to last child birth/ menopause. Amount of pus was $50 \mathrm{ml} / 400 \mathrm{ml}$ with $1 / 3$ rice grain/s. Urinary retention was in one and other had vaginal discharge but none of them had fowl smelly vaginal discharge, which was present in an exceptional case, where rice grain was in the uterotubal junction.

Postoperative period was uneventful with the catheter kept for 24 hours after surgery; Pus was sterile, kept on mild antibiotic coverage for a week with an average hospital stay of five days. Histopathology was suggestive of chronic inflammatory changes, without any malignancy. There was a case of adenomyosis in one of the histopathological study.

\section{DISCUSSION}

Rice grain as foreign body has been reported from ophthalmology alone and this could be the second publications of its kind.$^{13}$ And, such a finding although rare, yet, is not very surprising. Nepal being an agricultural country with majority of women indulged in farming and having to working in rice field with fallen womb or uterine prolapse. This Himalayan country has recognized UVP as a common morbidity. Scenario of early marriage, unattended childbirth, and resumption of work in early puerperium, the process going over and over again in a vicious cycle in the similar fashion repetitively and with very short birth spacing is a hard fact. ${ }^{14}$

In situation of uterine prolapse where cervix protrudes below the introitus vaginalis, it is possible for rice grain to enter the open parous cervical os, make its way via cervical canal, moving forwards into the uterine cavity. This can be realized from this study by the very presence of foreign body, rice grain at various locations starting from upper part of cervical canal, endometrial cavity, cornu-fundal region finally toward the intramural/interstitial portion of the fallopian tube, demonstrating internal microenvironment of uterus, responsible for transfer of any item as though it were motile sperm., ${ }^{9,12}$

In this study, the rice grain/s that accessed the uterine cavity is envisioned to have gotten retained there inside utero owing to the menopausal status governed by the absence of menstrual blood flow which otherwise was unable to flush out the foreign body. The rice grain retention symptoms, such as abdominal pain, dysuria, urinary retention and smelly vaginal discharge although are related to foreign body producing symptoms, but went unnoticed due to the rarity of the condition preoperatively.

One striking novel in built association of foreign body and pyometra is established herein, that too in UVP. Otherwise pyometra has been attributed to postoperative complication of reconstructive prolapse surgery. ${ }^{15}$ Pyometra formation do have risk of undergoing spontaneous perforation leading pyoperitoneum and luckily we were saved from this complication. ${ }^{16,17}$

\section{CONCLUSION}

Multiparous, postmenopausal women with major degrees of uterovaginal prolapse are predisposed to the liability of the entry of rice grain in utero through the cervix fallen out from the vaginal introitus and directly coming in contact with tiny foreign body and permitting their ascent in the cavity, sometime giving rise to huge problems, like pyometra. 


\section{REFERENCES}

1. Roy KK, MittalS, Verma A. Removal of an intrauterine foreign body retained for 12 years. Int J Gynaecol Obstet 1996 Aug; 54(2):185-186.

2. Harnsberger HR, Lee TG, Mukuno H, Melendez MG. Unusual intrauterine objects: potential pitfalls in ultrasonographic identification. J Ultrasound Med 1983 Apr;2(4):169-172.

3. Hunger C, Ring A. Chicken bones in the uterus-an exceptional reason for sterility. Zentralbl Gynakol 2001 Oct; 123(10):604-606.

4. Balakrishnan V. Rare foreign body in uterus. Ir Med J 1999 Jan-Feb;92(1):246-247.

5. Cetinkaya K, Kumtepe $Y$, Ingec M. Minimally invasive approach to cases of lost intra-uterine device: A 7-year experience. Eur J Obstet Gynecol Reprod Biol 2011 Nov; 159(1): 119-121.

6. Farghaly SA, Mathie JG. Retained Grafenberg ring for 39 years discovered during abdominal hysterectomy. Aust $\mathrm{N}$ Z J Obstet Gynaecol 1980 Nov;20(4):248-250.

7. Dajani YF, Khalaf SM. Intrauterine bone contraceptive device: an accident of nature. Fertil Steril 1985 Jan;43(1):149-150.

8. DF Osborne. Attempted Abortion with Retention of an Intrauterine Foreign Body. Can Med Assoc J 1964 Feb 15;90(7):494-495.

9. Lachman E, Czernobilsky B, Ben-David M, Vlodavsky E, Lifschitz-Mercer B, Mammet Y. Prolonged retention of laminaria fragments: a rare complication of induced abortion. Obstet Gynecol 2004 May;103(5 Pt 2):1128-1130.
10. Tiufekchieva E. Corpus alienum in the uterus-diagnostic and therapeutic hysteroscopy. Akush Ginekol (Sofiia) 2007; 46(5):28-32

11. Bettocchi S, Di Spiezio Sardo A Pinto L, Guida M, Castaldi MA, Ceci O, Nappi C. Hysteroscopic removal of gauze packing inadvertently sutured to the uterinecavity: report of 2 cases. J Minim Invasive Gynecol 2009 Jan-Feb;16(1):88-91.

12. Borgatta L, Barad D. Prolonged retention of laminaria fragments: an unusual complication of laminaria usage. Obstet Gynecol 1991 Nov;78(5 Pt 2):988-990.

13. Joseph T. Paddy grain injury of the eye. A study of 277 cases. Br J Ophthalmol 1968 Feb;52(2):191-197.

14. Dhital R, Otsuka K, Poudel K C, Yasuoka J, Dangal G, Jimba M. Improved quality of life after surgery for pelvic organ prolapse in Nepalese women. BMC Women's Health 2013; 13:22. Available at: http://www.biomedcentral.com/14726874/13/22.

15. Roth TM. Pyometra and recurrent prolapse after Le Fort colpocleisis. Int Urogynecol J Pelvic Floor Dysfunct 2007 Jun; 18(6):687-688.

16. Todorović ND, Jordjević V, Antonijević S. Pyometra as a result of placement of an intrauterine device for 40 years and chronic endometritis. Srp Arh Celok Lek 2002 Nov-Dec; 130(11-12):409-411.

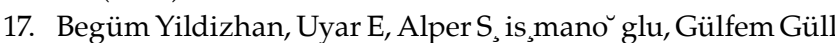
üo glu, Kavak ZN. Spontaneous perforation of pyometra: a case report. Infectious Diseases in Obstetrics and Gynecology 2006;Article ID 26786:1-3. 